\title{
MODEL PREDATOR-PREY MENGGUNAKAN RESPON \\ FUNGSIONAL TIPE II DENGAN PREY BERSIMBIOSIS \\ MUTUALISME
}

\author{
Ahmad Nasikhin dan Niken Larasati \\ Prodi Matematika, Fakultas Sains dan Teknik \\ Universitas Jenderal Soedirman \\ Email : ahmadnasikhin90@yahoo.co.id dan nk_larasati@yahoo.com
}

\begin{abstract}
In this paper, we study the dynamic behavior of predator-prey model using functional response type II and symbiotic mutualism of prey. One of the six equilibrium points is the coexistence point which is asymtotically stable. In this point, the number of prey and predator for a long term depends on the interaction level of prey to another species and the interaction level of another species to prey.
\end{abstract}

Keywords : predator-prey model, functional response type II, symbiotic mutualism, stability of equilibrium points.

ABSTRAK. Pada makalah ini, dikaji perilaku dinamik model predator-prey menggunakan respon fungsional tipe II dengan prey bersimbiosis mutualisme. Satu dari enam titik kesetimbangan model merupakan coexistence point yang bersifat stabil asimtotis. Titik tersebut bersifat stabil asimtotis. Pada titik tersebut, untuk jangka waktu yang lama, jumlah prey dan predator sangat dipengaruhi oleh tingkat interaksi prey terhadap spesies lain maupun tingkat interaksi spesies lain terhadap prey.

Kata kunci : model predator-prey, respon fungsional tipe II, simbiosis mutualisme, kestabilan titik kesetimbangan.

\section{PENDAHULUAN}

Di dalam lingkungan hidup, interaksi (hubungan timbal balik atau saling mempengaruhi) terjadi baik antar makhluk hidup dengan sesamanya maupun dengan lingkungannya (Aryanto, 2012). Interaksi yang terjadi antar makhluk hidup dalam suatu lingkungan hidup, antara lain berupa simbiosis mutualisme, kompetisi (persaingan), dan predasi. Predasi merupakan hubungan antara mangsa (prey) dan pemangsa (predator). Model matematika yang 
menggambarkan hubungan predasi dinamakan model predator-prey ( Edwards dan Penney, 2008).

Model predator-prey yang paling sederhana adalah model LotkaVolterra. Model ini hanya memodelkan hubungan antara predator dan prey saja. Padahal pada kenyataannya di beberapa lingkungan hidup terdapat hubungan predasi yang mana prey bersimbiosis mutualisme dengan spesies lain. Contohnya adalah interaksi predasi antara burung prenjak (Prinia familiaris) sebagai predator dengan kupu-kupu skipper (Taractrocera archias) sebagai prey dan bunga cente (Lantana camara) yang bersimbiosis mutualisme dengan kupu-kupu skipper. Dalam hal ini, simbiosis mutualisme antara bunga cente dengan kupu-kupu skipper diasumsikan mengakibatkan kedua populasi bertambah.

Afiati (2001), telah menurunkan model predator-prey dengan prey bersimbiosis mutualisme dengan spesies lain. Namun pada model tersebut tidak diperhitungkan waktu yang diperlukan predator untuk menangani prey (handling time) yaitu waktu untuk berburu, membunuh, makan, dan mencerna makan. Alexei (1997) dan Gutierrez (1996) menggunakan respon fungsional tipe II untuk menyertakan handling time pada model predator-prey tanpa simbiosis mutualisme. Oleh karena itu, pada makalah ini, model predator prey dengan prey bersimbiosis mutualisme akan dikembangkan dengan menyertakan respon fungsional tipe II untuk memperhitungkan handling time .

\section{MODEL}

Asumsi-asumsi yang digunakan untuk memudahkan dalam penurunan model predator-prey menggunakan respon fungsional tipe II dengan prey bersimbiosis mutualisme adalah sebagai berikut :

1. populasi bersifat tertutup, 
2. apabila tidak ada interaksi antara prey dan predator serta spesies lain, maka pertumbuhan prey dan spesies lain mengikuti model logistik dan penurunan predator mengikuti model Malthus,

3. model predator-prey yang dikaji terdiri dari satu predator dan satu prey, serta prey bersimbiosis mutualisme dengan satu spesies,

4. simbiosis mutualisme antara prey dengan spesies lain mengakibatkan kedua populasi bertambah, dan

5. respon predator yang digunakan adalah respon fungsional tipe II dan respon numerikal yang sebanding dengan respon fungsional tipe II.

Variabel-variabel dan parameter-parameter yang digunakan untuk menurunkan model tercantum pada Tabel 1. Selanjutnya, untuk menyederhanakan penulisan, $P(t)$ ditulis akan ditulis dengan $P, Q(t)$ ditulis akan ditulis dengan $Q$, dan $R(t)$ ditulis akan ditulis dengan $R$.

Tabel 1. Variabel-variabel dan parameter-parameter yang digunakan pada model

\begin{tabular}{|c|c|c|c|c|}
\hline Simbol & Definisi & Jenis & Syarat & Satuan \\
\hline$P(t)$ & Jumlah spesies $P$ pada saat $t$ & variabel & $P(t) \geq 0$ & ekor \\
\hline$Q(t)$ & Jumlah prey pada saat $t$ & variabel & $Q(t) \geq 0$ & ekor \\
\hline$R(t)$ & Jumlah predator pada saat $t$ & variabel & $R(t) \geq 0$ & ekor \\
\hline$a$ & $\begin{array}{l}\text { Tingkat pertumbuhan intrinsik } \\
\text { spesies } P\end{array}$ & parameter & $0<a \leq 1$ & $\begin{array}{l}\text { per satuan } \\
\text { waktu }\end{array}$ \\
\hline$K_{1}$ & Daya dukung lingkungan spesies $P$ & parameter & $K_{1}>0$ & ekor \\
\hline$\alpha$ & $\begin{array}{l}\text { Tingkat interaksi spesies } P \text { terhadap } \\
\text { prey }\end{array}$ & parameter & $0<\alpha \leq 1$ & $\begin{array}{c}\text { per ekor } \\
\text { satuan waktu }\end{array}$ \\
\hline$b$ & Tingkat pertumbuhan intrinsik prey & parameter & $0<b \leq 1$ & $\begin{array}{l}\text { per satuan } \\
\text { waktu }\end{array}$ \\
\hline$K_{2}$ & Daya dukung lingkungan prey & parameter & $K_{2}>0$ & Ekor \\
\hline$\beta$ & $\begin{array}{l}\text { Tingkat interaksi prey terhadap } \\
\text { spesies } P\end{array}$ & parameter & $0<\beta \leq 1$ & $\begin{array}{c}\text { per ekor } \\
\text { satuan waktu }\end{array}$ \\
\hline$c$ & $\begin{array}{l}\text { Tingkat interaksi predator terhadap } \\
\text { prey }\end{array}$ & parameter & $0<c \leq 1$ & $\begin{array}{c}\text { per ekor } \\
\text { satuan waktu }\end{array}$ \\
\hline$h$ & Waktu penanganan satu prey & parameter & $h>0$ & waktu \\
\hline$\gamma$ & $\begin{array}{l}\text { Efisiensi reproduksi predator akibat } \\
\text { interaksi predator terhadap prey }\end{array}$ & peluang & $0<\gamma<1$ & \\
\hline$e$ & Tingkat kematian predator & parameter & $0<e \leq 1$ & $\begin{array}{l}\text { per satuan } \\
\text { waktu }\end{array}$ \\
\hline
\end{tabular}


Berdasarkan variabel, parameter, dan asumsi yang digunakan, dapat ditentukan perubahan jumlah populasi spesies $P$, perubahan jumlah populasi prey, dan perubahan jumlah populasi predator terhadap waktu sebagai berikut.

1. Perubahan jumlah populasi spesies $P$ terhadap waktu.

Perubahan jumlah populasi spesies $P$ dipengaruhi oleh ada atau tidaknya interaksi dengan populasi prey. Saat tidak terjadi interaksi dengan populasi prey, maka pertumbuhan populasi spesies $P$ mengikuti model logistik dengan daya dukung lingkungan $K_{1}$ dan tingkat pertumbuhan intrinsik spesies $P$ sebesar $a$. Dengan demikian, populasi spesies $P$ akan bertambah dengan laju $a P\left(1-\frac{P}{K_{1}}\right)$. Asumsi simbiosis mutualisme antara prey dengan spesies lain mengakibatkan kedua populasi bertambah. Oleh karena itu, apabila terjadi interaksi antara spesies $P$ dengan prey sebesar $\alpha$, maka populasi spesies $P$ bertambah dengan laju $\alpha P Q$. Jadi laju perubahan jumlah populasi spesies $P$ terhadap waktu dapat dinyatakan sebagai

$$
\frac{d P}{d t}=a P\left(1-\frac{P}{K_{1}}\right)+\alpha P Q
$$

2. Perubahan jumlah populasi prey terhadap waktu.

Perubahan jumlah populasi prey dipengaruhi oleh ada atau tidaknya interaksi dengan populasi spesies $P$ dan populasi predator. Saat tidak terjadi interaksi dengan populasi spesies $P$ dan predator, maka pertumbuhan populasi prey mengikuti model logistik dengan daya dukung lingkungan $K_{2}$ dan tingkat pertumbuhan intrinsik prey sebesar $b$. Jadi populasi prey akan bertambah dengan laju $b Q\left(1-\frac{Q}{K_{2}}\right)$. Asumsi simbiosis mutualisme antara prey dengan spesies lain mengakibatkan kedua populasi bertambah. Oleh karena itu, apabila terjadi interaksi antara prey dengan spesies $P$ sebesar $\beta$. maka populasi prey bertambah dengan laju $\beta P Q$. Untuk handling time, respon fungsional yang digunakan adalah respon 
fungsional tipe II, yaitu $\frac{c Q}{c h Q+1}$ yang menyatakan jumlah prey yang dimangsa per predator per satuan waktu. Oleh karena itu, apabila terjadi interaksi antara predator dengan prey, maka populasi prey berkurang dengan laju sebesar $\frac{c Q}{c h Q+1} R$. Jadi laju perubahan jumlah populasi prey terhadap waktu dapat dinyatakan sebagai

$$
\frac{d Q}{d t}=b Q\left(1-\frac{Q}{K_{2}}\right)+\beta P Q-\frac{c Q}{\operatorname{ch} Q+1} R .
$$

3. Perubahan jumlah populasi predator terhadap waktu

Perubahan jumlah populasi predator dipengaruhi oleh ada atau tidaknya interaksi dengan populasi prey. Saat tidak terjadi interaksi dengan populasi prey, maka populasi predator berkurang mengikuti model Malthus dengan tingkat kematian predator sebesar $e$. Diasumsikan respon numerikal yang menyatakan jumlah predator yang diproduksi per predator per satuan waktu. sebanding dengan respon fungsional yaitu $\gamma \frac{c Q}{c h Q+1}$. Oleh karena itu, apabila terjadi interaksi antara predator dengan prey, maka populasi predator bertambah dengan laju sebesar $\gamma \frac{c Q}{c h Q+1} R$. Jadi laju perubahan jumlah populasi predator terhadap waktu dapat dinyatakan sebagai

$$
\frac{d R}{d t}=-e R+\gamma \frac{c Q}{c h Q+1} R
$$

Berdasarkan persamaan (1), (2), dan (3) diperoleh model predator-prey menggunakan respon fungsional tipe II dengan prey bersimbiosis mutualisme dengan spesies lain berupa sistem persamaan diferensial sebagai berikut: 


$$
\begin{aligned}
& \frac{d P}{d t}=a P\left(1-\frac{P}{K_{1}}\right)+\alpha P Q \\
& \frac{d Q}{d t}=b Q\left(1-\frac{Q}{K_{2}}\right)+\beta P Q-\frac{c Q}{c h Q+1} R \\
& \frac{d R}{d t}=-e R+\gamma \frac{c Q}{c h Q+1} R .
\end{aligned}
$$

Sistem (4) dapat ditulis kembali dalam bentuk

$$
\begin{aligned}
& \frac{d P}{d t}=a P-g P^{2}+\alpha P Q \\
& \frac{d Q}{d t}=b Q-f Q^{2}+\beta P Q-\frac{c Q}{\operatorname{ch} Q+1} R \\
& \frac{d R}{d t}=-e R+\gamma \frac{c Q}{\operatorname{ch} Q+1} R
\end{aligned}
$$

dengan $g=\frac{a}{K_{1}}$ dan $f=\frac{b}{K_{2}}$.

Titik kesetimbangan model predator-prey menggunakan respon fungsional tipe II dengan prey bersimbiosis mutualisme pada sistem (5) diperoleh jika $\frac{d P}{d t}=0, \frac{d Q}{d t}=0$, dan $\frac{d R}{d t}=0$. Jika $\frac{d P}{d t}=0$, diperoleh $P$ nullclines, yaitu $P=0$ atau $P=\frac{a+\alpha Q}{g}$. Jika $\frac{d Q}{d t}=0$, diperoleh $Q$-nullclines, yaitu $Q=0 \quad$ atau $\quad b-f Q+\beta P-\frac{c R}{c h Q+1}=0$. Jika $\frac{d R}{d t}=0$, diperoleh $R$ nullclines, yaitu $R=0$ atau $-e+\gamma \frac{c Q}{c h Q+1}=0$.

Titik kesetimbangan diperoleh dengan cara mencari titik perpotongan antara P-nullclines, $Q$-nullclines, dan $R$-nullclines. Dengan demikian, diperoleh enam titik kesetimbangan dari sistem (5), yaitu 


$$
\begin{aligned}
& T E_{0}=(0,0,0), T E_{1}=\left(\frac{a}{g}, 0,0\right), T E_{2}=\left(0, \frac{b}{f}, 0\right), \\
& T E_{3}=\left(0, \frac{e}{c(\gamma-e h)}, \frac{\gamma(b \gamma c-b e c h-f e)}{c^{2}(\gamma-e h)^{2}}\right), \\
& T E_{4}=\left(\frac{a f+\alpha b}{g f-\beta \alpha}, \frac{g b+\beta a}{g f-\beta \alpha}, 0\right) \text { dan } \\
& T E_{5}=\left(\frac{a c(\gamma-e h)+\alpha e}{g c(\gamma-e h)}, \frac{e}{c(\gamma-e h)}, \frac{b g \gamma c(\gamma-e h)-g f e \gamma+\beta a \gamma c(\gamma-e h)+\beta \alpha e \gamma}{g c^{2}(\gamma-e h)^{2}}\right) .
\end{aligned}
$$

Agar komponen spesies prey dan predator pada $T E_{3}$ berada pada titik kesetimbangan positif diasumsikan $h<\frac{\gamma}{e}$ dan $h<\frac{\gamma}{e}-\frac{f e}{e c b}$. Agar komponen spesies $P$ dan prey pada $T E_{4}$ berada pada titik kesetimbangan positif diasumsikan $K_{1} K_{2}>\frac{a b}{\beta \alpha}$. Agar komponen spesies $P$, prey, dan predator pada $T E_{5}$ berada pada titik kesetimbangan positif diasumsikan bahwa $h<\frac{\gamma}{e}$ dan $h<\frac{\gamma}{e}-\frac{(g f-\beta \alpha)}{c(b g+\beta a)}$ dengan $g f>\beta \alpha$. Selanjutnya, diperoleh bahwa $T E_{0}, T E_{1}, T E_{2}$, dan $T E_{3}$ bersifat tidak stabil, sedangkan $T E_{4}$ bersifat stabil asimtotis dengan syarat $K_{1} K_{2}<\frac{a b}{\beta \alpha}$ dan $h>\frac{\gamma}{e}-\frac{(g f-\beta \alpha}{c(g b+\beta \alpha)}$. Sementara itu, $T E_{5}$ bersifat stabil asimtotis dengan syarat $\alpha>f$,

$$
\left(\frac{-a c(\gamma-e h)-\alpha e}{c(\gamma-e h)}\right)\left(b+\frac{\beta a c(\gamma-e h)+\beta \alpha e-2 f e g}{g c(\gamma-e h)}-E\right)+\frac{\gamma E e}{\gamma}-\frac{\beta e D}{c(\gamma-e h)}>0,
$$

dan 


$$
\begin{aligned}
& \left(E-b-\frac{\beta a c(\gamma-e h)+\beta \alpha e-2 f e g}{g c(\gamma-e h)}-\frac{-a c(\gamma-e h)-\alpha e}{c(\gamma-e h)}\right) \\
& \left(\left(\frac{-a c(\gamma-e h)-\alpha e}{c(\gamma-e h)}\right)\left(b+\frac{\beta a c(\gamma-e h)+\beta \alpha e-2 f e g}{g c(\gamma-e h)}-E\right)+\frac{\gamma E e}{\gamma}-\frac{\beta e D}{c(\gamma-e h)}\right) \\
& >\left(\frac{E e a c(\gamma-e h)+E e^{2} \alpha}{c(\gamma-e h)}\right) .
\end{aligned}
$$

\section{SIMULASI MODEL}

Simulasi dilakukan untuk mengetahui pengaruh adanya spesies $P$ yang bersimbiosis mutualisme dengan prey pada model predator-prey menggunakan respon fungsional Tipe II. Simulasi dilakukan pada $T E_{5}$ karena $T E_{5}$ merupakan coexistence point yaitu setiap komponen pada $T E_{5}$ tidak ada yang mengalami kepunahan. Nilai parameter yang digunakan untuk simulasi ini adalah

$a=0,36, K_{1}=15,6, b=0,462, K_{2}=154, h=0,05, c=0,032, \gamma=0,85$, dan $e=0,456$ sehingga $g=0,023$ dan $f=0,003$, sedangkan nilai $\beta$ dan $\alpha$ berbeda-beda. Titik kesetimbangan model, nilai eigen dan kestabilan dengan nilai $\beta$ dan $\alpha$ berbeda-beda dapat dilihat pada Tabel 2 dan Tabel 3.

Berdasarkan Tabel 2, semakin besar nilai $\beta$, maka saat setimbang nilai $P$ dan $Q$ tetap, sedangkan nilai $R$ semakin besar. Artinya, semakin besar tingkat interaksi prey terhadap spesies $P$, maka dalam jangka waktu yang lama jumlah spesies $P$ dan prey tetap, sedangkan jumlah predator semakin banyak. Berdasarkan Tabel 3, semakin besar nilai $\alpha$ maka saat setimbang nilai $P$ dan $R$ semakin besar, sedangkan nilai $Q$ tetap. Artinya, semakin besar tingkat interaksi spesies $P$ terhadap prey, maka dalam jangka waktu yang lama jumlah spesies $P$ dan predator semakin banyak, sedangkan jumlah prey tetap. 
Tabel 2. Titik kesetimbangan, nilai eigen, dan kestabilan $T E_{5}$ dengan perubahan nilai parameter $\beta$

\begin{tabular}{|l|c|c|l|}
\hline \multicolumn{1}{|c|}{$\beta$} & $\begin{array}{c}\text { Titik Kesetimbangan } \\
\beta\end{array}$ & Nilai Eigen & \multicolumn{1}{c|}{ Kestabilan } \\
\hline 0,0019 & $(18,056 ; 17,226 ; 14,277)$ & $(-0,417 ;-0,019 \pm 0,443 i)$ & stabil asimtotis \\
\hline 0,005 & $(18,056 ; 17,226 ; 16,075)$ & $(-0,421 ;-0,016 \pm 0.468 i)$ & stabil asimtotis \\
\hline 0,05 & $(18,056 ; 17,226 ; 42,167)$ & $(-0,444 ;-0,006 \pm 0,738 i)$ & stabil asimtotis \\
\hline 0,1 & $(18,056 ; 17,226 ; 71,157)$ & $(-0,453 ; 0,023 \pm 0,949 i)$ & tidak stabil \\
\hline 0,11 & $(18,056 ; 17,226 ; 76,956)$ & $(-0,454 ; 0,026 \pm 0,985 i)$ & tidak stabil \\
\hline
\end{tabular}

Tabel 3. Titik kesetimbangan, nilai eigen, dan kestabilan $T E_{5}$ dengan perubahan nilai

parameter $\alpha$

\begin{tabular}{|l|c|c|c|}
\hline \multicolumn{1}{|c|}{$\alpha$} & $\begin{array}{c}\text { Titik Kesetimbangan } \\
(P ; Q ; R)\end{array}$ & Nilai Eigen & Kestabilan \\
\hline 0,009 & $(22,393 ; 17,227 ; 15,261)$ & $(-0,526 ;-0,018 \pm 0,454 i)$ & stabil asimtotis \\
\hline 0,01 & $(23,142 ; 17,227 ; 15,331)$ & $(-0,545 ;-0,013 \pm 0,455 i)$ & stabil asimtotis \\
\hline 0,02 & $(30,632 ; 17,227 ; 16,028)$ & $(-0,735 ;-0,004 \pm 0,461 i)$ & stabil asimtotis \\
\hline 0,029 & $(37,373 ; 17,227 ; 16,656)$ & $(-0,908 ; 0,005 \pm 0,467 i)$ & tidak stabil \\
\hline 0,03 & $(38,121 ; 17,227 ; 16,726)$ & $(-0,927 ; 0,006 \pm 0,467 i)$ & tidak stabil \\
\hline
\end{tabular}

\section{KESIMPULAN}

Dari enam titik kesetimbangan model terdapat satu titik kesetimbangan yang merupakan coexistence point. Hasil simulasi pada titik kesetimbangan tersebut menunjukkan bahwa semakin besar tingkat interaksi prey terhadap spesies lain, maka dalam jangka waktu yang lama jumlah spesies lain dan prey tetap, sedangkan jumlah predator semakin banyak ; dan semakin besar tingkat interaksi spesies lain terhadap prey, maka dalam jangka waktu yang lama jumlah spesies lain dan predator semakin banyak, sedangkan jumlah prey tetap.

\section{DAFTAR PUSTAKA}

Afiati, A. (2001) Analisis Kestabilan Model Dinamik Mutualistik. Bogor: Institut Pertanian Bogor.

Alexei, S. (1997) Quantitative Population Ecology. On-Line Lectures. Departement of Entomology. Virginia Tech. Blacksburg. USA.

Aryanto, S. (2012) Aplikasi Extended Kalman Filter pada Model Mangsa Pemangsa. Bandung: Universitas Pendidikan Indonesia. 
Edwards, C. H. dan Penney, D. E. (2008) Elementary Differential Equations. 6th Ed. New Jersey: Pearson Education.

Gutierrez, A. P. (1996) Applied Population Ecology a Supply-Demand Approach. New York: John Wiley \& Sons. 